\title{
Anthropocentrism and Speciesism in the Context of Environmental Studies. A Synoptic Introduction
}

\author{
Maria Vita Romeo \\ (Università degli Studi di Catania; mariavitaromeo@unict.it) \\ ORCID: 0000-0002-9925-7679

\section{Sara Sgarlata} \\ (Università degli Studi di Catania; sara.sgarlata@amu.edu.pl) \\ ORCID: 0000-0001-8166-2556
}

This new special volume of Ethics in Progress was inspired by the need to address the issue of anthropocentrism as the key concept in the light of which original and innovative readings of the human-environment relationship are provided, through a remodelling of frequently occurring problems in the field, i.e., the theoretical foundations and conceptual intercorrelations between human-centred narrations and attitudes toward the environment ${ }^{1}$.

Starting from the 1960s onwards, the cumulation of scientific data regarding the ecological crisis has profoundly changed humans' understanding of the environment, as well as that of their own relationship with it in a context that is, however, profoundly changed by modern science and technological civilization. Since then, a revision process applied to traditional ethical theories - as well as to the set of moral principles making up their core - has taken place. Environmental ethics was from the very beginning oriented towards a theoretical deconstruction of the cultural (including religious and philosophical) foundations on which disruptive human attitudes were supposedly rooted. What initially had been a critical appendix to traditional anthropocentrism then went on to consolidate as an autonomous theoretical corpus, serving as a guiding paradigm for all environmental challenges, so that nowadays it is even possible to speak of multiple families of environmental ethics.

Environmental ethics was therefore born in the early 1970s as an extension of applied ethics, in the guise of a "post-disciplinary" field (at that time) with respect to the Western ethical system, and was grounded on a worldview that placed human distinctiveness as being based in the fact that humans are the privileged value-givers and value-holders in the world. According to Bartolommei (1995, 40-41), by anthropocentrism we mean 
the conception according to which nature exists apart from humans, for whom in nature nothing has value unless it satisfies some human-serving interest, need or preference. Consequently, even assuming that nature has some kind of value, a differential treatment for humans and non-human nature would be legitimized, by principle.

The rejection of anthropocentrism constituted the dominant, if not foundational, ethical commitment of environmental ethics and philosophy, as well as its most effective political and intellectual justification (Minteer 2009, 4). However, what is strongly conveyed by the concept of anti-anthropocentrism is the need to postulate the non-instrumental, intrinsic value of natural things: only in this way will it be possible to develop an authentic ethics of the environment, rather than an ethics of exploitation (albeit conscious) of the environment. As Aldo Leopold (see Norton 1991, 92) pointed out, the earth is not only the soil sustaining material interdependency relationships, but also the cultural background of all values. If we fail to secure sound scenarios of the future existence of the earth, then we eliminate the foundation of all added values. Similarly, what environmental studies promotes is a set of scientifically informed and ethically inspired guidelines for effective pro-environment actions.

Furthermore, special room for discussion has been made with respect to the notion of speciesism, which is often regarded as a synonym of anthropocentrism. According to Faria and Paez's (2014) critical reconstruction, these two closely linked concepts are rather likely to explain different phenomena, although belonging to the same dominion. The authors introduce a different understanding of the notion of speciesism. Speciesism

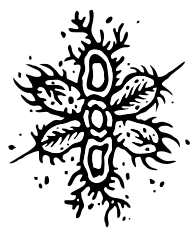
is the "unjustified preferential consideration of members of a particular nonhuman species against members of others," or the "unjustified disadvantageous consideration of members of a particular nonhuman species, though not of members of other nonhuman species" (Faria \& Paez 2014, 99). Anthropocentrism would be, then, a particular form of speciesism, consisting of the unjustified advantageous consideration of members of the human species to the detriment of those of non-human ones.

Closely connected with this topic, Enrico Giannetto's (Università degli Studi di Bergamo) contribution was guided by the topical question of the intimate correlation between epistemic anthropocentrism - that is, the fact that it is not possible to think as nonhumans - and moral anthropocentrism. "Understanding non-human beings is impossible within the framework of human philosophy, as it will imply some kind of dialogue with non-human beings, achieved through an experience of participant observation aimed at understanding and learning animal philosophies" (Gianetto 2020, in this volume). In contrast to Gianetto's argument, a specifically human mode of thinking, i.e., reasoning by concepts articulated in words and further processed in dialogical and discursive forms, emphasized as the distinctive feature of post-Socratic Western philosophies, would lead to a rationalistic reduction of nature to a world of abstractions and pure linguistic signs. The devouring semiotization of the world is thus addressed as constituting the culturalphilosophical foundations of the human-specific predatory impulse to dominate (and 
understand) other living beings anthropocentrically. Speciophilosophy is thus introduced as a counter-philosophy, which promotes the extension of the philosophy of dialogue to animals, regarded as subjects of their own animal philosophies.

Biagio Tinghino (Azienza Socio-Sanitaria Territoriale in Brianza) focuses on the historical narrations, current theories, and psychological and ethical motives that influence dietary choices. Special attention is devoted to the beneficial effects and significantly positive impact of vegetarian diets, as well as vegan diets, on both physical health and environmental sustainability. "Alongside nutritional theories derived from an evolutionary narrative or favored by psychological traits, there is much discussion today about the compatibility between the various proposed dietary models, on the one hand, and environmental development and planetary economic sustainability, on the other hand. The expression 'ecological nutrition' has many implications (Metz \& Hoffmann 2009; Schneider \& Hoffmann 2011). This concept encompasses several dimensions, including health and environment, but also economy and society." (Tinghino 2020, this volume). By addressing the idea that environment-related concerns in fact do affect some specific nutritional models, Tinghino launches an invitation to reflect on how the private beliefs that shape one's own lifestyle, on the one hand, and the publicly shared attitudes toward the environment, on the other, jointly contribute to create economical and societal development orientations.

According to Cecilia Della Torre (Università Cattolica del Sacro Cuore di Milano), "Sloterdijk uses technology to refer to a safe haven, as opposed to a natural and evil environment that has to be modified and redefined by humans. Indeed, Sloterdijk refuses the idea of nature as the protective good mother of every human being. According to him, human beings can no longer find safety and protection in nature, but rather they do so in their own actions and the related by-products. Therefore, technology appears to be the key for human salvation against this dangerous environment" (della Torre 2020, in this volume) by means of an Ark or "mechanical uterus". Her article advocates for the importance of philosophical readings of the integration, or co-belonging, between humans and the environment for designing human societies. In her critical - both provocative and inspiring - deconstruction of Peter Sloterdijk's project called technopolitics, she shows how the relationship between nature and culture intersects the problem of the axiomatic groundings that give shape to the political life, also offering new insights into the redefinition of the role of ethics as repristinating the (inverted) balance between good and evil.

Paolo Trianni (Pontificia Universitas Gregoriana; Centro Studi Cristiani Vegetariani) develops an original discussion on the literary and historical prodromes of an emerging, innovative hermeneutics of the Sacred Scriptures and Patristic literature, intended to detect the presence of crucial passages that would justify the consolidation of the so-called theology of vegetarianism. As Trianni argues, "the vegetarian choice must basically be connected with the logic of the beatitudes. In other words, it falls within the 
logic of the new law taught in the Sermon on the Mount, in the sense that in the beatitudes there is no longer simple obedience to the Ten Commandments, but rather an invitation to perfection, holiness and excellence. From this point of view, vegetarianism, even if it cannot be an obligation, should be perceived as a duty by anyone who feels challenged to live a morally and spiritually higher life" (Trianni 2020, this volume). The article also sheds light on the historical events and characters (belonging not only to the sphere of the Roman Church, but also to that of heretical cults), as well as on the doctrinal controversies that contributed to strengthening the carnivorous custom in the Judeo-Christian world. By valorizing Christian authors that speculated in favour of and embraced a vegetarian life-style, Trianni advocates for sensitizing Christian thought toward contemporary issues related to anthropocentrism and speciesism - here by means of theology itself.

Two book reviews then follow. Firstly, Alicja Dłużewicz (Adam Mickiewicz University in Poznań) reviews Eric Nelson's book Daoism and Environmental Philosophy: Nourishing Life (2021) which unfolds Chinese intellectual and practical approaches toward the human-environment relationship. Secondly, Anna Szklarska's (Pedagogical University of Cracow) review regards the book recently edited by Dorota Probucka (2020), which gathers many contributions and perspectives on The Ethical Condemnation of Hunting.

Finally, a compilation (in French) based on the original report on clinical survey conducted in Brussels by Josephine Joteyko and Varia Kipiani - both of whom had expertise in human physiology - with 43 vegetarians (Enquête scientifique sur les

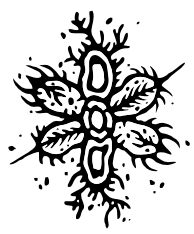
Végétariens de Bruxelles, Conférence donnée à la Société végétarienne de Belgique, le 4 décembre 1906, pp. 1-77) closes the issue. The excerpts, specifically selected for Ethics in Progress in collaboration with Ilana Löwy (Paris) and Ewa Nowak (Poznań), abridge the most remarkable findings on vegetarian dietary habits, as shown to be beneficiary for human development in many respects (physical and mental health, welfare, and physical and intellectual efficiency).

We sincerely thank all the reviewers that contributed to the publication of this issue. We are obliged as well to Marcin Jan Byczyński and Stephen Dersley for their fundamental contributions and diligent engagement with the edition process. We value and appreciate it to the greater extent. A special thank goes to Noemi Sgarlata, whose graphics enriched the visual look of the issue. "Support for Scientific Journals" granted to Ethics in Progress by the Polish Ministry of Science and Higher Education (2019-2021) made possible essential improvements in all papers and abstracts making up this special issue. 


\section{References}

Bartolommei S. 1995. Etica e natura. Una rivoluzione copernicana in etica?. Roma-Bari: Laterza.

Faria C. \& Paez E. 2014. "Anthropocentrism and Speciesism: Conceptual and Normative Issues," Revista de Bioética y Derecho 32:93-103.

Metz M. \& Hoffmann I. 2009. "Effects of Vegetarian Nutrition - A Nutrition Ecological Perspective," Nutrients 2(5):496-504. DOI: 10.3390/nu2050496.

Minteer B. 2009. Nature in Common? Environmental Ethics and the Contested Foundations of Environmental Policy. Philadelphia: Temple University Press.

Norton B. G. 1991. Towards Unity among Environmentalists. New York: Oxford University Press.

Schneider K. \& Hoffmann I. 2011. "Nutrition Ecology - a Concept for Systemic Nutrition Research and Integrative Problem Solving," Ecology of Food and Nutrition 50(1). DOI: $10.1080 / 03670244.2010 .524101$. 